\title{
The "Pandemic" of Disinformation in COVID-19
}

\author{
Fabio Tagliabue ${ }^{1} \cdot$ Luca Galassi $^{1}$ (D) $\cdot$ Pierpaolo Mariani $^{1}$
}

Accepted: 28 July 2020 / Published online: 1 August 2020

(C) Springer Nature Switzerland AG 2020

\begin{abstract}
In recent years, mass media and social networks have played an important role in disseminating information regarding public health. During the COVID-19 epidemic, misinformation and fake news have represented an important issue generating confusion and insecurity among the population. In our analysis, we investigate the role of mass media as a critical element during the SARS$\mathrm{CoV}-2$ outbreak that has influenced the public perception of risk.
\end{abstract}

Keywords COVID-19 $\cdot$ Mass-media $\cdot$ Fake news $\cdot$ Public health

The role of the mass media and social networks has always been fundamental in the management of health-related information.

During this current pandemic, people have been continually searching for information regarding the coronavirus infection.

In many cases, people have unfortunately found themselves overwhelmed with news containing fake reports and misinformation, which, for those without the right skills, can be complicated to digest.

This situation has generated confusion within the population and has also influenced some statements by public figures and politicians, which have in turn have led to further repercussions on public opinion. The general population has, in good faith, taken the information, including fake news, most relevant to their own personal situation and has used it to formulate their own interpretation of the pandemic.

At the beginning of the pandemic, the medical community also played a role in making the situation even more confusing by giving, in some cases, inaccurate and sometimes contradictory indications on COVID-19. There have been numerous media debates about who advocated distinct conflicting positions. Two opposite positions could be recognized from the numerous interviews between members of the medical

This article is part of the Topical Collection on COVID-19

Luca Galassi

lucagalassimd@gmail.com

1 General Surgery Unit, ASST Bergamo Est, P.O. Pesenti Fenaroli, Via G. Mazzini 88, 24022 Alzano Lombardo, Bergamo, Italy community: on the one hand those who were inclined to spread alarming news and on the other who had optimistic ideas that supported a non-hazardous nature of COVID-19.

A few weeks after the start of the pandemic, comments from non-specialists in infectious-respiratory problems could be seen in the mainstream media. It seemed as though the entire scientific community (gastroenterologists, nephrologists, surgeons, neurologists...) were releasing statements and writing articles as if they were the main experts of COVID-19.

People were so overwhelmed by this flood of information that they did not have time to understand it correctly. The massive presence in the mass media of doctors who expressed their opinions, sometimes not supported by scientific evidence, could be interpreted as a desire to appear rather than the need to provide the correct indications. The alarming tone of some experts has caused in some cases a rush to purchase personal protective equipment (PPE) and alcoholic detergents; this fact partially contributed to the lack of PPE in the clinical sector and to a disproportionate increase in the prices of these products.

In psychologically fragile subjects, an exacerbation of psychiatric pathologies [1] and determined headline stress disorder [2] has been manifested. Initial, and overly optimistic medical statements that judged the epidemic as a simple influenza lowered social attention on the COVID-19 pandemic and instilled in some people conspiracy or denial ideas supported by statements by some doctors and non-medical professionals who said, "it's just a flu." [3]

The poor perception of the risks related to COVID-19 infection also manifested itself despite the exponential growth of infections and deaths. In Italy, on March 21, 2020, while 
the maximum increase of new cases was recorded (6557), 11,411 people were sanctioned for not respecting the lockdown [4]. In the USA, the lockdown, imposed to reduce contagion, has been strongly opposed and its purpose diminished by comments in the media from public figures who have a greater following than the scientific community in influencing public opinion.

Similarly, the mass media, in an attempt to gain visibility, have perhaps unwittingly misinformed the public whenever a new experimental treatment started. The beginning of an experimental treatment was reported by newspapers who reported it as the decisive discovery to combat SARS-CoV-2, thus accentuating people's sense of security [5].

Moreover, the search for journalistic scoops has triggered a race to find responsibility for the COVID-19 pandemic, and has thus reduced the trust of people in the national and international institutions responsible for preserving public health.

Social media platforms are well known for the spread of misinformation and denial of scientific literature [6]. Fake news has reduced the relevance to evidence-based precautions promoted by national health services [7], and perhaps, little has been done to stop this virus on social networks. The WHO has offered a WhatsApp service to refute fake news, but unfortunately the rapid, viral spread of disinformation on social networks has been so widespread that we have in fact witnessed the appearance of attitudes harmful to health.

In some cases, patients refused to take ibuprofen or other anti-inflammatory drugs because of the erroneous idea that they could increase the chances of getting infected with the coronavirus [8]. Misleading information about treatment for COVID-19 has resulted in an increasing number of vitamin D abuse and even mass poisoning from methanol intake [9]. After the lockdown, in countries where social distancing and the use of face masks were mandated, news of correlation between cancer and mask coverings appeared on social networks [10].

The lockdown and consequent social distancing has resulted, especially in those residing in highly infected areas, in a posttraumatic stress syndrome (PTSD) characterized by anxiety, sleep disturbances, distress, and a drop in the tone of the mood with a decrease of positive mood such as happiness and serenity and an increase of sadness or boredom [11, 12]. Misinformation and fake news contributed to the onset of PTSD and headline stress disorder cases [2]. The consequences of these disorders have not only had effect in the peak infection phase but will also have future repercussions. The historical importance of the COVID-19 pandemic is such that, also in the future, COVID-19-related news will be published cyclically in the mass media and on social networks. Poor quality information may in the future amplify anxiety to the state of panic especially in the event of a new wave of infections; people will relive the moments of the first phase of the peak of COVID-19 and will return to look for information to safeguard their health and that of their loved ones.

Fake news also stimulated indignation with the consequent reaction of people for an alleged injustice. The incomplete or incorrect news reported by the mass media and then reworked on social networks have also focused attention on possible errors of some hospital structures. In some cases, this will mean that patients will be reluctant to go to hospitals or medical centers in the fear of becoming victims of medical errors or to be at a greater risk of contagion. Healthcare workers, subject to PTSD risk, may have an additional psychological burden as they may suffer lawsuits brought by relatives of victims of COVID-19 who will accuse them of not having undertaken for their loved one's therapies that the mass media described as effective, but which were actually experimental. Even an effective vaccine against COVID-19 could run the risk of falling victim of fake news by reducing the number of people who will join the vaccination campaigns.

The rapid evolution of the COVID-19 pandemic has not permitted immediate and certain scientific data. Considering this, the need therefore arises that, especially in the event of pandemics, doctors must provide the public only with evidence-based information in a simple and shared way in order to avoid misinterpretation and misunderstanding. Better coordination between the medical community, governments, and the mass media is therefore needed to avoid the spread of disinformation through different channels, limiting the dissemination of fake news and thereby better engaging the general public to adhere to correct guidelines.

Author Contributions All authors conceived and planned this paper, devised the project and the main conceptual ideas. Moreover, all authors provided critical feedback and helped shape the research, analysis, and writing the manuscript.

\section{Compliance with Ethical Standards}

Conflict of Interest The authors declare that they have no conflicts of interest.

\section{References}

1. Pereira-Sanchez V, Adiukwu F, El Hayek S, Bytyçi DG, GonzalezDiaz JM, Kundadak GK, et al. COVID-19 effect on mental health: patients and workforce. Lancet Psychiatry. 2020;7:e29-30. https:// doi.org/10.1016/s2215-0366(20)30153-x.

2. Dong M, Zheng J. Letter to the editor: headline stress disorder caused by Netnews during the outbreak of COVID-19. Health Expect J. 2020;23:259-60. https://doi.org/10.1111/hex.130553.

3. Il Giornale. Fontana: "Il coronavirus è poco più di una normale influenza". 2020. https://www.ilgiornale.it/news/politica/fontanacoronavirus-poco-pi-normale-influenza-1831891.html Accessed $25 \mathrm{Feb} 2020$.

4. Italian ministry of the interior. Monitoraggio dei servizi di controllo inerente le misure urgenti per il contenimento della diffusione del 
virus COVID-19. 2020. https://www.interno.gov.it/sites/default/ files/modulistica/monitoraggio_serviz_controllo_giornaliero_21.3. 2020.pdf Accessed 2 Jun 2020.

5. Nigerian Tribute. Antimalarial Drug Has Curative Effect On Coronavirus, Chinese Experts Say. 2020. https://www.msn.com/ en-za/news/other/chloroquine-found-effective-againstcoronavirus-cures-12552-patients-in-china/ar-BB10cWjT accessed 20 Feb 2020.

6. Rosenberg H, Syed S, Rezaie S. The Twitter pandemic: the critical role of Twitter in the dissemination of medical information and misinformation during the COVID-19 pandemic. CJEM. 2020. https://doi.org/10.1017/cem.2020.361.

7. O'Connor C, Murphy M. Going viral: doctors must tackle fake news in the covid-19 pandemic. BMJ. 2020. https://doi.org/10. 1136/bmj.m1587.

8. Maassenvandenbrink A, De Vries T, Danser AHJ. Headache medication and the COVID-19 pandemic. J Headache Pain. 2020. $\mathrm{https}$ ://thejournalofheadacheandpain.biomedcentral.com/articles/ 10.1186/s10194-020-01106-5 Accessed 2 Jun 2020.

9. Soltaninejad K. Methanol mass poisoning outbreak: a consequence of COVID-19 pandemic and misleading messages on social media.
Int J Occup Environ Med. 2020. https://doi.org/10.34172/ijoem. 2020.1983.

10. Il Tempo. Le mascherine fanno venire il cancro? La teoria di Montanari fa infuriare Burioni https:/www.iltempo.it/cronache/ 2020/05/23/news/mascherine-cancro-stefano-montanari-robertoburioni-vaccini-novax-bufale-coronavirus-fake-news-1327771/ accessed 23 may 2020.

11. Forte G, Favieri F, Tambelli R, Casagrande M. COVID-19 pandemic in the Italian population: validation of a post-traumatic stress disorder questionnaire and prevalence of PTSD symptomatology. Int J Environ Res Public Health. 2020;17. https://doi.org/10.3390/ ijerph17114151.

12. Forte G, Favieri F, Tambelli R, Casagrande M. The enemy which sealed the world: effects of COVID-19 diffusion on the psychological state of the Italian population. J Clin Med. 2020;9. https://doi. org $/ 10.3390 / \mathrm{jcm} 9061802$.

Publisher's Note Springer Nature remains neutral with regard to jurisdictional claims in published maps and institutional affiliations. 